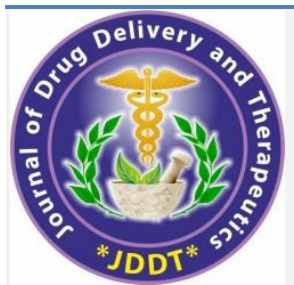

Open Access Full Text Article

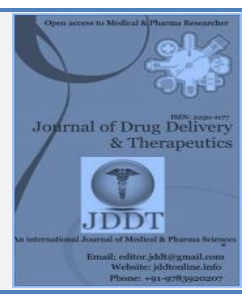

\title{
Assessment of Disease Knowledge, Medication Adherence, HRQOL in COPD Patients at a South Indian Tertiary Care Hospital
}

\author{
Somanaboina Padmakar1*, R.B. Purandhar Chakravarthy², P. Sai Karthik², B.U. Charitha², T. Harini², P. \\ Vijaya Narsimha Reddy ${ }^{3}$, \\ ${ }^{1 *}$ Assistant Professor, Department of Pharmacy Practice, P. Rami Reddy Memorial College of Pharmacy, Kadapa 516003, Andhra Pradesh, India \\ ${ }^{2}$ Pharm-D Intern, Department of pharmacy Practice, P. Rami Reddy Memorial College of Pharmacy, Kadapa 516003, Andhra Pradesh, India
}

${ }^{3}$ Assistant. Professor of General Medicine (GGH) Rajiv Gandhi Institution of medical sciences, Kadapa 516003 Andhra Pradesh, India

\begin{tabular}{ll}
\hline Article Info: & \\
\hline & Article History: \\
& \\
&
\end{tabular}

\section{Cite this article as:}

Padmakar S, Chakravarthy RBP, Karthik PS, Charitha BU, Harini T, Reddy PVN, Assessment of Disease Knowledge, Medication Adherence, HRQOL in COPD Patients at a South Indian Tertiary Care Hospital Journal of Drug Delivery and Therapeutics. 2021; 11(5):57-60

DOI: http://dx.doi.org/10.22270/jddt.v11i5.5019

\section{*Address for Correspondence:}

Dr. S. Padmakar, Assistant Professor, Department of Pharmacy Practice, P. Rami Reddy Memorial College of Pharmacy, Kadapa 516003, A.P., India

\section{Abstract}

Introduction: Chronic obstructive pulmonary disease (COPD) is a progressive, lifethreatening disease of the lungs, gradually causes breathlessness and predisposes to exacerbations and serious illness. The main objectives of the study are to evaluate disease knowledge, medication adherence, and health-related quality of life among COPD patients.

Methodology: A Hospital-based, single-entered prospective observational study was conducted at a government general hospital, Andhra Pradesh. India after ethical committee approval. This study was conducted for 6 months with a sample size of 80 patients.

Results: According to our study, the majority of the patients $36(45 \%)$ don't have disease knowledge, where a few numbers of patients 7 (8.75\%) is having disease knowledge as per BCKQ score values. $11.25 \%$ of patients have the lowest MMAS scores whereas $58.75 \%$ were found to have higher MMAS scores and $37.5 \%$ of total patients have higher CAT scores, and $12.5 \%$ of patients have lower CAT scores.

Conclusion: We found that majority of the patients have poor disease knowledge, lower adherence to medication regimens, and substandard HRQOL.

Keywords: COPD knowledge, medication adherence, and HRQOL.

\section{INTRODUCTION}

Chronic obstructive pulmonary disease (COPD) is a progressive airflow limitation in the lungs, which is not fully reversible by medication. Management of COPD is a $10 \%$ medication and $90 \%$ education program. COPD leads to physical disability, hospitalization, loss of productivity, and high cost to patients and society. COPD shows marked impairment in health-related quality of life (HRQOL). Acute exacerbation COPD (AECOPD) associated with physical disability limits daily activities thereby, negatively affecting HRQOL. Patients' awareness and knowledge about the disease are important in leading a normal life ${ }^{1-4}$. Adherence is defined as "the extent to which a person's behavior (in terms of taking medications, following diets, or executing lifestyle changes) coincides with medical or health advice" 5 . Patient non-adherence is one of the best recorded but least understood health-related actions ${ }^{6}$. COPD patients are nonadherent with their treatment recommendations both intentionally and unintentionally ${ }^{7}$. However, better medication adherence was associated with a decrease in the number of emergency department visits and length of hospital stay among patients with chronic respiratory diseases $^{8}$.

\section{METHODOLOGY}

\section{Study design and setting:}

A hospital-based, single - centered prospective observational study was conducted at a government general hospital (RIMS) Kadapa, which is a tertiary care hospital providing free inpatient and outpatient care under the control of the government of Andhra Pradesh India. The study duration was for 6 months conducted in the department of general medicine between November 2020 to May 2021.

\section{Study population:}

80 COPD patients were enrolled in the study based on GOLD inclusion criteria. The recruited patients were above 18 years old irrespective of gender. Severe unconscious patients were excluded from the study. 


\section{Data collection:}

The information was gathered using a valid and authentic data collection form. Three questionnaires were given to the patients to assess their knowledge of COPD, medication adherence, and HRQOL. The questionnaires are transcribed into Telugu depending on the study participants' location.

\section{BCKQ:}

BRISTOL COPD knowledge questionnaire is a self-employed questionnaire to assess patient education to subsist with COPD. It consists of 13 questions with 5 items relating to pathophysiology of COPD, breathing and exercise, energy conservation, and medications (scoring: correct responses = 1 , incorrect responses $=0$, and unsure responses receiving no score). A higher score indicates a greater knowledge level.

\section{MMAS:}

MORISKY medication adherence scale measures adherence through four yes/no response items accounts for the various reasons for nonadherence namely; forgetting, carelessness, stopping when feeling better, and stopping when feeling worse (scoring: 'yes'=0,'no'=1).

MMAS score range between 0 and 4 . Higher score lower medication adherence

CAT: (COPD assessment test) CAT is a Simple and quick patient completed instrument that can quantify the impact of COPD on the patient's health. Scores range from 1-40 Score $>30$ indicates worse QOL

10-20 indicates moderate QOL $<10$ good QOL.

\section{Ethical considerations:}

The study was performed after the approval from the ethical committee of the government general hospital (RIMS) Kadapa. Written informed consent was obtained from the study participants or their caretakers before the initiation of the research. The ICF was formulated in the Telugu language.

\section{Statistical analysis:}

The scores obtained from the administration of questionaries were inserted in to excel sheet for their analysis. Descriptive strategies like average, mean, percentage, and standard deviation were used to formulate the results.

\section{RESULTS}

Out of 80 patients, 54(68\%) were males and 26(32\%) were females. The majority of the patients $32(40 \%)$ were under the age group of 61-70 years. (Figures 1 and 2).

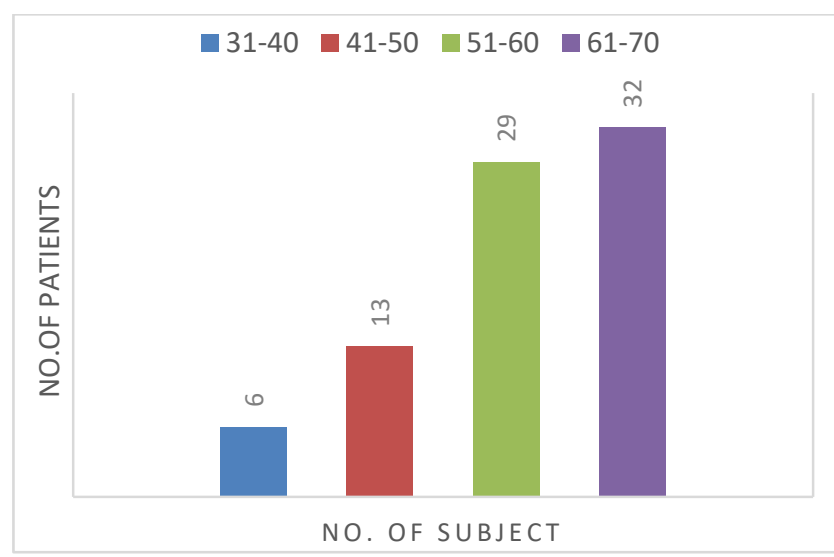

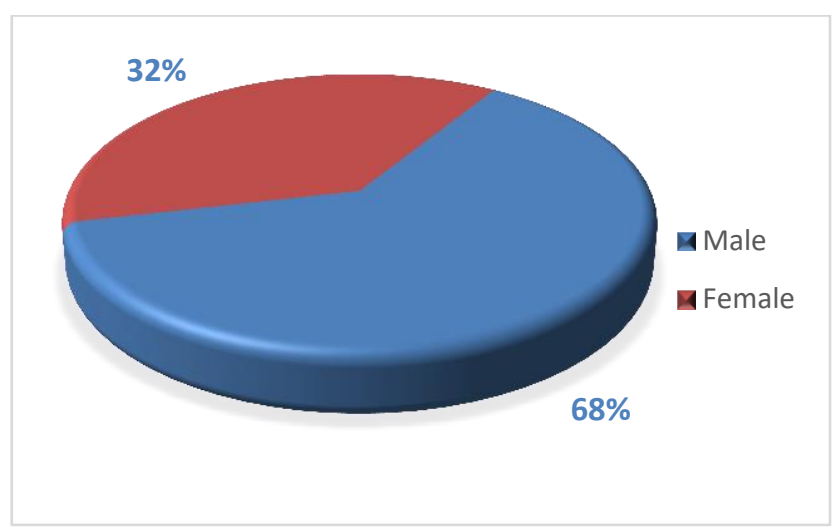

Figure 2: Distribution based on Gender

Out of 80 patients, $36(45 \%)$ patients are having a BCKQ score of $11-20$ and $7(8.75 \%)$ patients are having a score of 51-60. which indicates most of the patients is having less disease knowledge. (Figure 3).

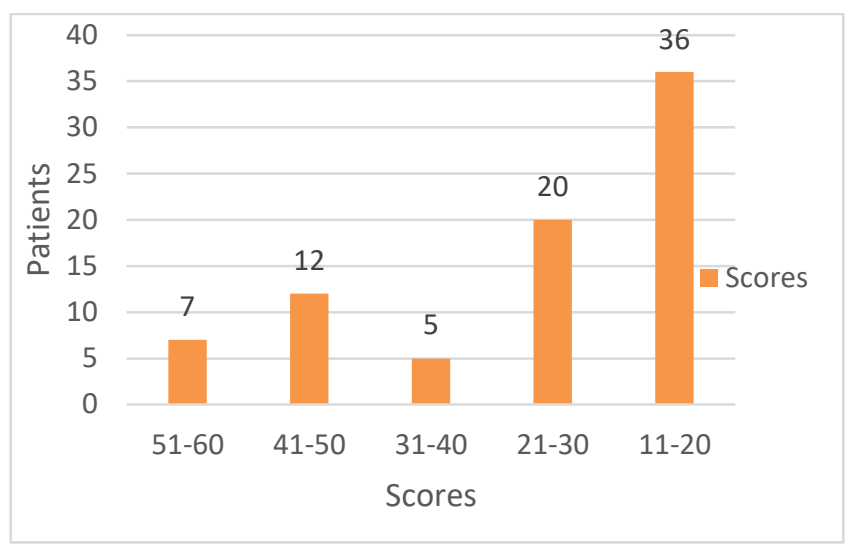

Figure 3: Disease knowledge in COPD patients

Among 80 patients, 42 patients were having an MMAS score of $>2,16$ and10 patients were having a score of 1 and 2 respectively. 12 patients were having a score of 0 , which implies the majority of the patients were having less medication adherence. (Figure 4).

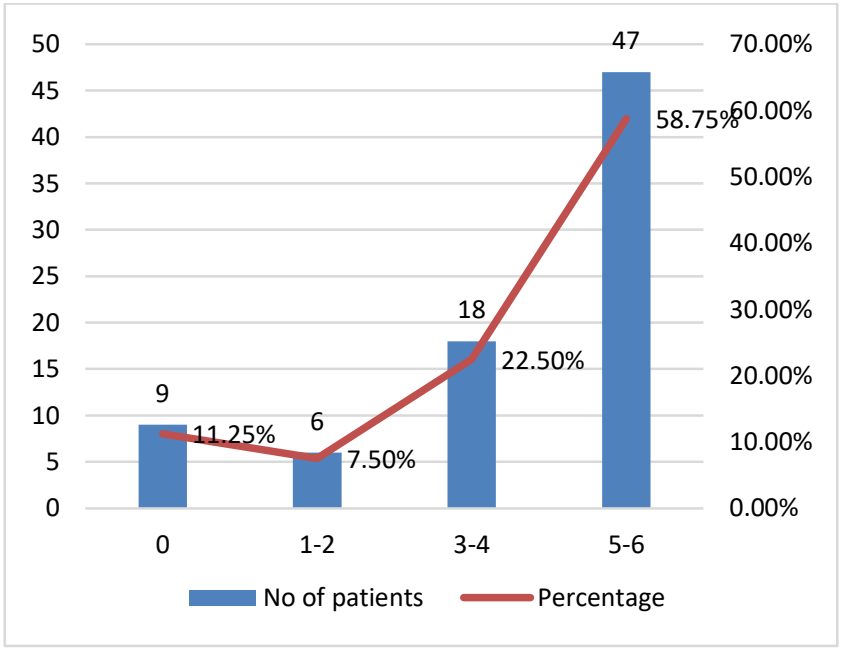

Figure 4: Medication adherence among COPD patients

Among 80 patients 30 patients were having CATS scores of $>3021$ and 19 patients were having scores between 21 - 30 and $19-20$ respectively. 10 patients were having a score of $<10$ which is suggestive of poor quality of life (Figure 5).

Figure 1: Distribution based on Age 


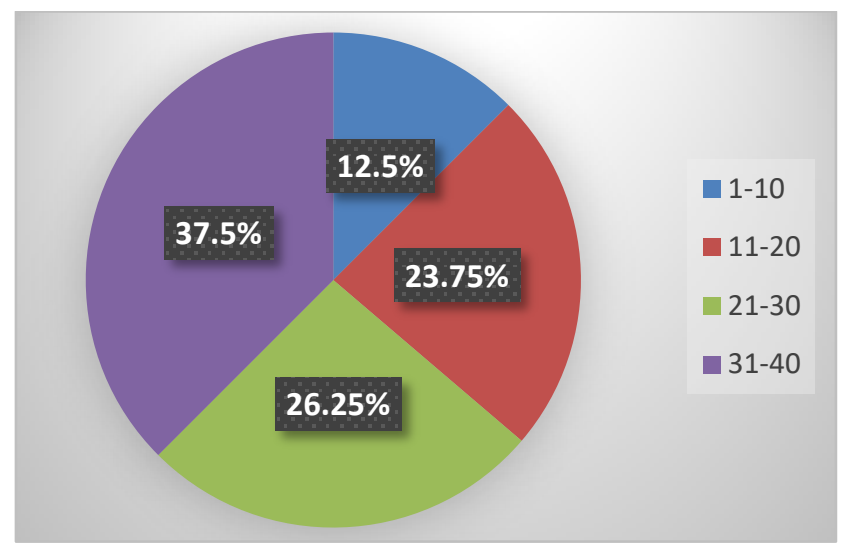

Figure 5: HRQL in COPD patients

\section{DISCUSSION}

Out of 80 patients in our study, 32 (40\%) were in the 60-70 year age range. Patients aged 50-59 years are represented by 29 (36.25\%), 40-49 years are represented by $13(16.25 \%)$, and 30-39 years are represented by 6. (7.5\%). This research is comparable to the one below. According to Teli et al ${ }^{9}$., the study found that the majority of patients (53 percent) were between the ages of 60 and 80, while the least number of patients were between the ages of 20 and 40 . (12\%).

The demographic data of 80 COPD patients indicated that male patients were found to be predominantly having COPD $(63 \%)$ when compared to female patients, which is only (32\%). similar reports were found by K.V. ramanath et al ${ }^{10}$. and faheemuddin MD et al ${ }^{11}$., these studies showed males are more in COPD diseases when compare to females.

Among the total number of patients included in the study, the number of smokers was predominantly high $(68 \%$ found only in males) when compared to non-smokers (20\%-males). There are no smokers in the female group. This study is similar to the following study. According to the Avinash et $\mathrm{al}^{9}$., the number of smokers was predominantly high (87\%) when compared to the non-smokers (13\%).

In our study, comorbidities was found with COPD in decreasing order were cardiovascular diseases (43.75\%), diabetes mellitus (18.75\%), others including gastroesophageal disorders, arthritis, skin disorders, obesity, (17.5\%), followed by cardiovascular diseases and diabetes mellitus (11.25\%). this study is similar to the following study. According to the avinash et $\mathrm{al}^{9}$., the study showed that comorbidities found with COPD were acute exacerbations $(27 \%)$, cor-pulmonale $(15 \%)$, hypertension $(10 \%)$. Coronary artery disease (8\%), diabetes mellitus (3\%), alcoholic hepatitis $(3 \%)$, chronic kidney disease $(3 \%)$, renal calculi (3\%), HCV (3\%), epistaxis (3\%), CCF (3\%), DCMP (3\%), ALD (2\%), cervical spondylosis (2\%), UTI (2\%), hypothyroidism (2\%), rheumatic arthritis (2\%), myocardial infarction (2\%), cholelithiasis (2\%), HBsAg (2\%).

The drug prescribing pattern of our study showed that out of 80 patients; the medications prescribed for COPD patients were glucocorticoids (90\%), anticholinergics (45, phosphodiesterase inhibitors (35\%), antibiotics (30\%), beta 2 adrenergic agonists (27\%), and leukotriene receptor antagonist (15\%). This study showed that glucocorticoids were the most commonly prescribed, followed by anticholinergics, phosphodiesterase inhibitors, antibiotics, beta 2 adrenergic agonists, leukotriene receptor antagonists. Similar reports were found by suhaj, A et $\mathrm{al}^{12}$. in which glucocorticoids were most commonly prescribed followed by anticholinergics, beta-adrenergic agonists, phosphodiesterase inhibitors, antibiotics, leukotriene receptor antagonist.

Out of 80 samples, the lowest BCKQ scores were $8.75 \%$ and highest scores were $45 \%$ of total COPD patients. High BCKQ scores indicate more disease knowledge it was supported by Raksha Thakrar et $\mathrm{al}^{13}$., the study suggests an imminent need to educate the public about the disease, the scope of pulmonary rehabilitation and its role in the management of COPD.

The lowest MMAS scores were found in $11.25 \%$ of total patients and highest scores were found in $75 \%$ of total samples. Higher the score lower the knowledge. The results are similar to following studies according to Jamie Bryant et $\mathrm{al}^{14}$. The study analyzed that COPD critical to optimising Patients out comes. There is a clear need for rigorous research to determine effective intervention for improving medication adherence for individual with COPD.

Faheemuddin MD et $\mathrm{al}^{11}$., concluded that there are no significant differences at baseline, followed by first follow up wasp $<0.01$, followed by second follow by wasp $<0.0001$. This clearly showed that there was a good improvement in they provided medication adherence behavior of COPD patients in intervention when compared to control because the intervention group it with effective counseling material.

\section{CONCLUSION}

In our study, Disease knowledge, Medication adherence and Health Related Quality of Life were analysed. We found that majority of the patients have poor knowledge about the disease, lower adherence with medication regimen and substandard Health Related Quality of Life. So structured clinical pharmacist intervention and appropriate education about the disease, medication regimen and its adherence, QOL, plays an important role in reduction of disease severity and improvement in patient care.

\section{Conflict interest: None}

\section{References}

(1) Agusti AG. Global initiative for chronic obstructive lung disease [Internet]. www.goldcopd.org. 2015 [cited 2020 Autumn 11]. Available from: https://goldcopd.org/\#

(2) Khdour MR, Kidney JC, Smyth BM, McElnay JC. Clinical pharmacyled disease and medicine management programme for patients with COPD. British journal of clinical pharmacology. 2009 Oct; 68(4):588-98. https://doi.org/10.1111/j.13652125.2009.03493.x

(3) Jarab AS, AlQudah SG, Khdour M, Shamssain M, Mukattash TL. Impact of pharmaceutical care on health outcomes in patients with COPD. International journal of clinical pharmacy. $2012 \mathrm{Feb}$; 34(1):53-62. https://doi.org/10.1007/s11096-011-9585-z

(4) Gupta D, Agarwal R, Aggarwal AN, Maturu VN, Dhooria S, Prasad KT, Sehgal IS, Yenge LB, Jindal A, Singh N, Ghoshal AG. Guidelines for diagnosis and management of chronic obstructive pulmonary disease: Joint ICS/NCCP (I) recommendations. Lung India: official organ of Indian Chest Society. 2013 Jul; 30(3):228. https://doi.org/10.4103/0970-2113.116248

(5) Haynes RB, Taylor DW, Sackett DL. Compliance in health care.

(6) George J, Kong DC, Thoman R, Stewart K. Factors associated with medication nonadherence in patients with COPD. Chest. 2005 Nov 1; 128(5):3198-204. https://doi.org/10.1378/chest.128.5.3198

(7) Dolce JJ, Crisp C, Manzella B, Richards JM, Hardin JM, Bailey WC. Medication adherence patterns in chronic obstructive pulmonary disease. Chest. 1991 Apr 1; 99(4):837-41. https://doi.org/10.1378/chest.99.4.837 
(8) Balakrishnan R, Christensen DB. Inhaled corticosteroid use and associated outcomes in elderly patients with moderate to severe chronic pulmonary disease. Clin Ther 2000; 22:452- 469. https://doi.org/10.1016/S0149-2918(00)89013-X

(9) Teli A. A Study of Drug Utilization and Prescribing Patterns of Drugs in Chronic Obstructive Pulmonary Diseased Patients (IPD and OPD) in Tertiary Care Hospital. Acta Scientific Pharmacology. 2020; 1:01-9.

(10) Ramanath KV, Balaji DB, Nagakishore CH, Kumar SM, Bhanuprakash M. A study on impact of clinical pharmacist interventions on medication adherence and quality of life in rural hypertensive patients. Journal of Young Pharmacists. 2012 Apr 1; 4(2):95-100. https://doi.org/10.4103/0975-1483.96623

(11) Faheemuddin MD, Ramaiah B, Kiran SS, Kumari BS, Vijayalaxmi M. Evaluation of medication adherence in COPD patients and their drug utilisation pattern. Chron Obstruct Pulm Dis. 2016; $1: 17$.

(12) Suhaj, A. (2015). Evaluation of Structured Individualized Pharmacist Intervention Programme on Economic Clinical and Humanistic Outcomes of COPD Patients in a Tertiary Care Hospital. Published. http://hdl.handle.net/10603/105681

(13) Thakrar R, Alaparthi GK, Kumar SK, Vaishali K, Zulfeequer CP, Aanad R. Awareness in patients with COPD about the disease and pulmonary rehabilitation: A survey. Lung India: Official Organ of Indian Chest Society. 2014 Apr; 31(2):134. https://doi.org/10.4103/0970-2113.129837

(14) Bryant J, McDonald VM, Boyes A, Sanson-Fisher R, Paul C, Melville J. Improving medication adherence in chronic obstructive pulmonary disease: a systematic review. Respiratory research. 2013 Dec; 14(1):1-8. https://doi.org/10.1186/14659921-14-109 